\title{
Information about information
}

\author{
ALAN GILCHRIST \\ Cura Consortium, Reino Unido, alangilchrist77@gmail.com
}

\begin{abstract}
Resumen
Se sostiene que, aunque el panorama de la información ha cambiado radicalmente, los principios básicos de la ciencia de la información siguen siendo válidos, y que a menudo indavertidamente siguien aplicándose, por lo que podrían volver a se de nuevo más ampliamente reconocidos. Este nuevo escenario se ilustra brevemente con algunos ejemplos seleccionados de su importancia, peligros e historias de éxito actuales. Están empezando a surgir nuevos modelos y enfoques, de los cuales se presentan algunos ejemplos. Es vital que sean alentados y apoyados para que la sociedad en su conjunto y, en particular, sus ciudadanos puedan estar mejor informados.
\end{abstract}

Palabras clave: Ciencia de la información. Organización del conocimiento. Metadatos. Teoría. Perspectivas. Casos de éxito.

\section{Introduction}

The title of this paper is taken from a remark made by Robert Fairthorne many years ago. An Information Scientist, but originally a mathematician, Fairthorne, well known for his commonsensical remarks, once said "Information Scientists do not give information, they give information about information". While this was true at the time that he said it, the advance of information technology, the interconnectedness of communications technology and the resultant increase of disintermediation have radically changed this basic aspect of information science in practice. This paper argues, however, that basic principles described in the literature of information science and repeated as recently as 2004 are still valid and might be redeployed, though with obvious difficulty, in the new electronic environment. This difficulty should be faced and understood, and tackled with a concerted effort by information scientists and allies in other disciplines.

\section{Traditional Information Science practice}

Expanding the pithy comment of Fairthorne's it may be seen that the task of the information scientist mediating between recipient and source involved:

\begin{abstract}
This paper argues that though the information landscape has radically changed, the basic tenets of information science are still valid, are often unwittingly being applied and may again become more widely recognized. This new landscape is briefly illustrated with some selected examples of its size, dangers and current success stories. New models and approaches are beginning to emerge and some examples of these are presented. It is vital that these are encouraged and supported so that society and its citizens may become better informed.
\end{abstract}

Keywords: Information science. Knowledge organization. Metadata. Theory. Perspectives. Success stories.

1. Understanding the request for information, including the want behind the request, and perhaps the use to which the recipient hopes it may be put.

2. Gauging the likelihood of the ability of the enquirer to assimilate any information contained in the item(s) retrieved. (It would be futile to answer a schoolchild's request for information on the solar system with an academic treatise by the Astronomer Royal of the United Kingdom).

3. Establishing an effective contact with a potential physical or personal source of information.

4. Helping in the formulation of an enquiry.

5. Assessing the relevance of the answers and an informed view of the reliability of the source.

These exchanges between enquirer and mediator and between mediator and source (face to face or via an electronic link) require interpretation, or what might more grandly be called hermeneutics. In the words of Zimmermann (2015) "The goal of interpretation is to make sense of a text or situation, to understand what they mean", and if that seems obvious, it should be remembered that failures in interpretation are experienced every day, either knowingly or not. Given the five 
potentially complex steps above, effective interpretations throughout the sequence may not be straightforward and may require a high degree of knowledge and empathy between the mediator and enquirer.

Zimmermann goes further in his discussion of hermeneutics when he states that "the goal of hermeneutics is understanding, and that although understanding may be guided by analytical principles, it cannot be reduced to them", and that "Understanding requires art", and "Understanding is knowledge in the deeper sense of grasping not just facts but their integration into a meaningful whole". In the case of the mediation as described above this integration is formed through discourse using language to arrive at a shared understanding of the actions to be performed from start to finish. To emphasise this point one must remember that language is complex and that understanding between two people must often depend on reiteration and the use of alternative and explanatory expressions. By replacing a human mediator with a machine we have lost much of this "knowledge in the deeper sense", and the searcher for information often works alone.

\section{The basics of Information Science}

Though the scope of Information Science may have expanded (in both theory and practice) it is worth going back to the work of Brian Vickery and Alina Vickery, notably in their seminal book Information Science in Theory and Practice (12). In the final chapter of their book, echoing the hermeneutic principle outlined above, they suggest that:

[...] information science should seek to increase our understanding of:

(1) The behaviour of people as generators, sources, recipients, and users of information, and as channel agents;

(2) The quantitative study of the population of messages - its size, growth rate, distribution, patterns of production and use;

(3) The semantic organization of messages and of channels that facilitates their identification by sources and recipients;

(4) Problems particularly associated with the functions of information storage, analysis and retrieval;

(5) The overall organization of information systems and their performance in transfer;

(6) The social context of information transfer, in particular its economics and politics.

This quotation has been reproduced in full because, in every respect, the constituent parts remain valid within the context of the contemporary world of electronic interconnection and social media, though will have to be modified in practice.

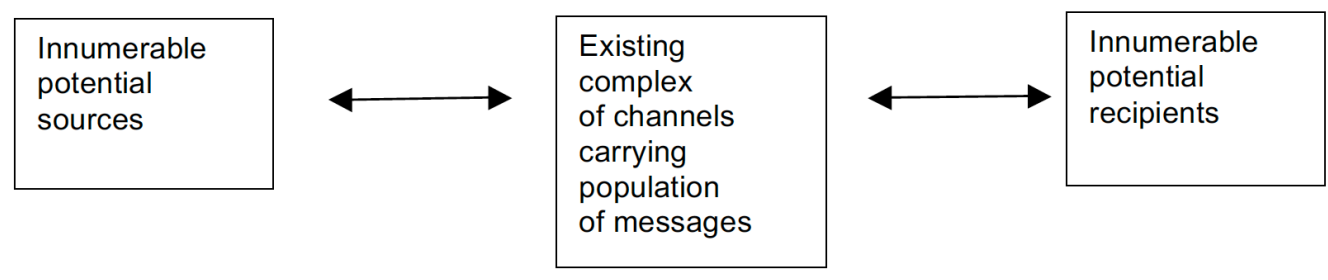

Figure 1 (adapted from Vickery and Vickery, 2004)

\section{Size and speed}

A small Figure from the book by the Vickerys (204) underlined the enormous task faced by information scientists when their book was published. That task facing information workers (and, it must be said, society as a whole) has now increased dramatically:

What is startling about this Figure are the currently enormous numbers reflected in each of the three boxes. It is almost meaningless to quote large numbers concerning the Internet, numbers that are increasing by the minute, but a short survey of some figures proposed by reputable sources taken at random from the Web may nevertheless serve as a reminder.

1. There were roughly one billion personal computers in the world at March 2014; and almost 48 million have been sold so far this year (at 15 March 2016).

2. There are now more active mobile devices in the world than people, some 7.2 billion gadgets, (though half of the world's population do not own one).

3. Another source claims there are some 2 billion smart-phones; and these each have the power of a supercomputer of 30 years ago. 
4. In September 2014 a milestone was reached when 1 billion websites were recorded.

5. There may, as of 2013 , have been some 152 million blogs, though many are abandoned by the user after a few weeks. More meaningfully, 1.13 million postings were recorded on the single day of 21 March 2015.

And searching the Internet produces big numbers too, not always with completely satisfactory results. For example, two searches on Google produced these results:

- Astrobiology: about 529,000 (hits) in 0.55 seconds

- Learning to play the ocarina: about 388,000 (hits) in 0.58 seconds.

The first of these searches produced, not surprisingly, a mixed bag of references on the first page, while the second (again, not surprisingly) produced a majority of relevant items. As an exhibition of enormous computing power and clever algorithms these figures are hugely impressive, but who looks beyond the first few pages to check for the possibility of interesting items, and would it matter if the search took one or two seconds? These may be trivial observations of detail, but they do raise the question of what value these figures have, other than to boast of the power of Google. More importantly, perhaps, they tend to lull the searcher into what might be a feeling of satisfaction that may be unwarranted, or a hurried 'that will do' reaction.

Admittedly, these observations are rather unfair to Google, considering the way in which it has made the Web accessible, but (in passing) it may be added that other search engines are not so impressive: one specialist blog search engine produced a first page of irrelevant hits in answer to the query 'Learning to play the ocarina' all being concerned with online video games - two involving 'Queen Ocarina'.

Another aspect of size is seen in the power and financial might of the GAFA quartet of Google, Apple, Facebook and Amazon, a power that is changing the landscape of large areas of information provision particularly in that of print on paper, affecting the newspaper sector and publishers and sellers of books. The size of the GAFA giants has also, perhaps, inhibited the growth of more specialised services though, as will be shown later in this paper, there are a number of interesting initiatives beginning to appear in the area of information processing and provision.

\section{Dangers of size, accessibility, speed and time}

Now that anybody with access to the Internet can be a 'publisher', there are new dangers of the abuse of free speech, most notably to be found in trolling, the dissemination of misinformation including that based on unfounded opinions and worse, intentional disinformation. Nigel Warburton (2009) (quoting Richard Posner) has noted four dangers relating to "irresponsible speech" on the Internet:

- Anonymity: making it easy to hide behind false, or even illegal, information.

- Lack of quality control: allowing the spread of inaccurate and misleading information and the publication of often libellous gripes and rumours concerning celebrities.

- Huge potential audience: tending to magnify any harm caused by false information.

- Antisocial people find their soul mates: possibly leading to antisocial acts by individuals emboldened by their perceived support.

Children are particularly vulnerable and a reputable newspaper in the U.K. has reported that "Up to three quarters of primary school children (i.e. ages 5 to 11) have online connections with people they don't know in the real world".

Even the amount of information churned out by the mass media is indigestible, particularly in the way in which it is used by the media to sell newspapers, and by politicians and others using the media, often guilty of spreading misinformation and even occasionally disinformation. The famous philosopher and author Umberto Eco (2002), in discussing the interplay between politicians and the newspapers, has observed

[...] with statements following one another day after day...the result is that the reader loses count and forgets what has been said ...the price, both for the press and the politician, is unreliability and a "who cares?' reaction from the man in the street".

These short-comings contribute to widespread assumptions of false information, often about emotive issues. For example, it has been reported in the British newspaper The Guardian that "Britons think that $£ 24$ out of every $£ 100$ spent (by the Government) on (social) benefits is claimed fraudulently when the official estimate is $70 \mathrm{p}$ ". This sort of misapprehension is not confined to the U.K. The current anti-immigration sentiment leads "Britons and Spaniards to think they have twice as many immigrants in their country as they actually do, the Italians, Belgians and French assume there are three times as 
many as there are, and the Poles more than thirty times". The same newspaper, in a short Editorial, draws attention to cyberwarfare and the deliberate intra-national dissemination of misinformation. In one instance the U.S Government discovered that "it had fallen victim to a hack attack on an unprecedented scale, with the security of the details of up to four million former and present employees apparently breached". The same newspaper discovered a building in St Petersburg staffed by paid bloggers to establish inoffensive online personalities in the comment sections of media outlets with the aim of seeding such outlets with pro-Putin or pro-Government remarks.

An article in the New Scientist by Baraniuk (2016) is also disturbing. It starts with a report of research undertaken on how the social web works, specifically on how different types of information are spread on Facebook by two different communities - one that shared science news articles and another that shared conspiracy theories. The research found that "science stories received an initial spike of interest and were shared frequently" while "conspiracy theories started off with a low level of interest but sometimes grew to be even more popular than the science stories overall". More importantly, showing how information bias can lead to an "echo chamber effect", it was found that in a study of 55 million Facebook users, "out of 50,000 posts debunking rumours, only 1 in 12 reached people who had shared the rumour in question". Baraniuk (2016), the author of this article puts forward five ways in which research has shown how the Internet twists the truth:

"Majority illusion, where groups within social networks tend to be influenced most by a small number of popular individuals.

- List ordering, the use of search engine optimisation to ensure that certain hits appear high up in the list of sites retrieved, which results in a feeling in the searcher that sites high on the list are more credible.

- Astroturfing, the invention of a wave of support or dissent manufactured by advertisers, political parties, or even governments.

- BOT democracy, whereby an army of Bots (web robots - software applications that run automated tasks (scripts)) is deployed to give an impression of, for example, a grass-roots policy (as was admitted by a Parliamentary candidate in London in 2012).

- Disinformation, deliberately planted false information. For example in 2014 Cynk Technology briefly became worth $\$ 6$ billion, after a barrage of tweets and emails promoting the stock flooded the Web. It turned out that the firm had no assets, no revenue and one employee.

Swamped with potential information and the pressure of time, and seduced by the advertising of the ubiquitous 'click' many users of IT suffer further problems. Research commissioned by KasperskyLab (2015) in a report under the title The Rise and Impact of Digital Amnesia. Why we Need to Protect what we no Longer Remember concluded that there was " a direct link between data available and a failure to commit that data to memory", defining Digital Amnesia as "Experience of forgetting information that you trust a digital device to store for you". Another piece of academic research, this one of the millennial generation by Taylor (2012) observes that "Millennial generation Web searchers proceed erratically through an information search process, make only a limited attempt to evaluate the quality or validity of information gathered, and may perform some level of 'backfilling' or adding sources to a research project before final submission". Clearly, the lack of any expert intermediation is to be regretted, though it is difficult to see how it might be installed.

Finally, in this section concerning some of the worst aspects of current problems in the world of information, it must be noted that even 'big business' is failing to address information problems adequately. After years of reports repeating that while senior management claimed to regard information as vital to their business, their own knowledge workers were dissatisfied with the level and quality of information provision. A report from Gartner, noted by Allan Foster (2014), predicts in a research study that "By 2017, 33\% of Fortune's organizations will experience an information crisis due to their inability to effectively value, govern and trust their enterprise information".

\section{All is not lost!}

After the first waves of uncertainty, curiosity, acceptance and delight in the new, it was probably inevitable that such a powerful device as the Internet would attract misuse and carry social problems. The previous section has indicated some of these problems, albeit in a piece-meal and subjective way, but it remains a fact that such problems do exist as individuals, groups and governments strive to sideline or ban the worst features and concentrate on making better sense of the whole. This section briefly reviews some of the important advances as well as some of the new developments. 


\subsection{Current success stories}

Despite the sorry state of 'enterprise search' as mentioned above, large databases continue to thrive and be interconnected to others. Medline, Agrovoc, Eurovoc and the shared database supplied by CERN for scientists worldwide working in the field of particle physics are some notable examples. New initiatives are springing up in the area of information provision with wide ambitions, for example the Europeana Project, whose betatest website (Surowiecky, 2004) invites users "...to explore 52,557,036 artworks, artefacts, books, videos and sounds from across Europe" with growing multilingual access. Europeana is just one example of systems using Linked Open Data (LOD) largely based on a complex array of standards laid down by W3C, the World Wide Web Consortium.

These standards are hugely important, indeed necessary. For example, the basic device for describing a resource known as the RDF (Resource Description Framework) is in the form of what is known as a 'triple', This is a statement based on 'subject-predicate-object', for example 'Michelle is the wife of - Barack Obama', and each of these three entities must then be given a URI (Universal Resource Indicator). It is clear that the diversity of possible meanings must also be dealt with so that, for example, two URIs containing the word 'Berlin' must be processed to distinguish between 'Berlin', the city and 'Berlin' the songwriter. This is, obviously, detailed and painstaking work.

In addition to LOD projects such as Europeana, other projects are building what might be termed 'hubs'. In technical network terms a hub is 'a common connection point', but this could be extended to include connection points carrying openly available information. One such is the DBpedia, a huge scheme which, in earlier times might have been described as an example of secondary publishing. The DBpedia is described by Lehmann et al (2012) as "a knowledge base that extracts structured, multilingual knowledge from Wikipedia and makes it available using Semantic Web and Linked Open Data technologies [...] the largest DBpedia knowledge base, extracted from the English edition of Wikipedia consists of 400 million facts that describe 3.7 million things". Expanding this idea of hubs, Javier Garcia Marco (2016) has called for better devices allowing browsing on the Web through "a semantic network of KOS", with a particular idea of creating such a network around a large facility such as Wikipedia.

\subsection{Radical movements}

With so much advertising and trivia on the surface web it is heartening to see a range of public facing and interactive websites being built by governments and some independent fact checking agencies. However, while this is to be welcomed, the range of sources. quantity and complexity of information can be daunting. For example:

- www.gov.uk is the official UK Government website, combining 24 Ministerial Departments and 331 other agencies and public bodies.

- www.data.gov.uk is the official UK Government website containing data sets released under the Government's Transparency Agenda.

But, perhaps somewhat confusingly,

- https://yougov.uk is an independent global market research and data company which has established "a community of 4 million people round the world who share their views".

At the time of writing this paper the campaign for the UK referendum on whether to remain in or leave the European Union was in full swing. Though the official Government policy favoured Remain, many Government members and even some Government Ministers favoured Leave. All the political parties were issuing their arguments on their own websites in addition to the websites of the two official campaign organizations 'Britain Stronger in Europe' and 'Vote Leave' (quoting their own versions of 'facts'). Thankfully, there is an independent and independently funded website (https://fullfact.org) dedicated to checking 'facts' disseminated on official websites, including all of the websites listed above, currently then with particular reference to the EU referendum debate. There is also a similar American website at (www.snopes.com) that in its own words "debunks urban legends, old wives' tales, fake news, shoddy journalism and political spin". Add to the above examples the plethora of facts, misinformation, disinformation and opinions disseminated on other websites and in the media and it becomes clear that the process of arriving at an objective and informed personal opinion is a daunting task.

In addition to outward looking websites, a number of central and local governments are now operating interactive sites. For example, Madrid (https://decide.madrid.es) under the banner "La ciudad que quieres será la ciudad que quieras" elicits responses to plans to remodel the Plaza Espana; while Paris (https://idee.paris.fr) with the headline "Madame la Maire j'ai une idée" invites ideas from its citizens. 
This attempt to gather comments and opinions has been related to the famous story of Francis Galton (cousin of Charles Darwin) and the country cattle fair where farmers were asked to guess, for a prize, the weight of a displayed ox, butchered and dressed. Galton took the tickets after the event and discovered that the average guess of all the entrants was remarkably close to the actual weight - in fact, one pound weight for an ox that weighed 1,198 pounds. This collective guess was not only better than the actual winner but also better than the guesses made by cattle experts at the fair. This discovery became known as "The wisdom of crowds" and lies behind some of the psychology in a number of websites being developed in a number of countries.

However, attractive as the idea of the wisdom of crowds is, tapping into it must be carefully planned. As the French writer Anatole France said "If fifty million people say a foolish thing, it is still a foolish thing", and there are more subtle problems to be avoided. For example. a piece of research carried out at ETH in Switzerland (14) asked two groups to suggest the answers to two questions: 'the length of the Swiss-Italian border' and 'the annual number of murders in Switzerland'. The research, not surprisingly, showed that as the amount of information that participants were given about each other's guesses increased, the range of guesses became narrower; tending towards a consensus to the detriment of accuracy. James Surowiecky has studied such phenomena more widely in his book The Wisdom of Crowds (Ball, 2014) in which he proposes "four key qualities that make a crowd smart". These are:

1. It needs to be diverse, so that people are bringing different pieces of information to the table.

2. It needs to be decentralized, so that no one at the top is dictating the crowd's answer.

3. It needs a way of summarizing peoples' opinions into one collective verdict.

4. And the people in the crowd need to be independent, so that they can pay attention mostly to their own information, and not worry about what everyone around them thinks.

One particularly ambitious project is being carried out by GovLab at New York University following encouragement from Barack Obama. This project has carried out an extensive review of other projects such as the 'Decide.Madrid' and 'Idée.Paris' mentioned above and is now researching new approaches and championing the activities of other agencies, as explained by Beth Simone Noveck in her book 'Smarter Citizens, Smarter State' (Noveck, 2015). Noveck wants "citizens with practical experience to sign up to a networked searchable 'Brains Trust'”, with accompanying advanced technology for its exploitation. The key to this ambition is to capture details on not only the qualifications, but also the experience of civil servants and to match these with similar databases of citizens. There are examples of the former, established by such agencies as the Department of Defense, but few examples of the latter, one being a New York database of citizens with language skills. Though Noveck's intentions are no doubt honourable, there are already some sceptics, some being nervous of surveillance, others unconvinced that such an enormous network will actually be capable of producing viable high-level policy decisions.

\section{Some conclusions}

\subsection{Image and language}

Sargon of Akkad, who reigned around 2250 BCE, has been called 'The Father of Libraries' and there is certainly much archaeological evidence of large and well-organized libraries in ancient Mesopotamia, particularly at Nineveh. The Assyrian word for librarian is translated as 'keeper of the tablets', and this image has persisted through the ages as the keepers of scrolls, codices and books, though librarianship has since embraced many other skills. Nevertheless, in the public mind libraries are usually large, often magnificent buildings full of shelves full of books. This image persists from Alexandria to the huge multilingual collections of $11^{\text {th }}$ Century Baghdad and Cordoba and through to the Vatican and today's National Libraries, not forgetting the University and Public Libraries - all highly visible and recognizable for what they are. The names of famous librarians have also persisted - Callimachus of Alexandria who devised a classified catalogue for the collection; Archibald Macleish, Chief Librarian of the Library of Congress and advisor to Franklin D. Roosevelt, and Jorge Luis Borges, Director of the National Library of Argentina - these last two also being internationally renowned writers and poets. So, the image of the imposing buildings are further enhanced by the renown of their supervisors.

Some 4,200 years after Sargon, the term 'Information Scientist' was first coined, later extended to 'Information Science'. These were not terms that became widely recognized and, indeed, the reaction in conversations that mentioned the terms soon became "Oh. you mean computers". In addition, in the public mind (except for the users in scientific and industrial establishments) there was no great physical evidence of their activity; and often in an industrial situation, the 'information department' was housed with the Research Department often separated on a different 
site. Today, it has to be admitted that any image that there might have been has further faded. But A. J. Meadows had this to say in a collection of essays published in 2009 (2009):

Both computer studies and business studies are much larger than information science in terms of number of researchers and financial support. Consequently, this merging of interests is also, to some extent, a submerging as can be seen in some of the departmental reorganizations at universities in the UK... The overall result is that the information science activities developed over the last 50 years have triumphed, but information science as a separate entity may be on the wane. If so, its final epitaph may well be that of (the architect) Sir Christopher Wren in St Paul's Cathedral: 'If you want a monument, look around you'.

\subsection{A resurgence?}

In 2002 in the UK the IIS (Institute of Information Scientists) was merged into the (LA) Library Association to form CILIP, the Chartered Institute of Librarians and Information Professionals. The former influence of the IIS was thus diminished, information science being included in the poorly defined term 'Information Professional'. By coincidence, in the same year, the older International Federation of Information and Documentation (FID) was disbanded. Now, in the UK few groups appear to be carrying on the ethos of the IIS except perhaps for the UK Chapter of the International Society for Knowledge Organization which, despite the somewhat grandiose title and sometimes abstract preoccupations of the parent body can at least boast, like librarians, of having tangible features: classification schemes, thesauri and other retrieval languages. It can also be observed that, in promoting the application of Knowledge Organization, the ISKO UK Chapter is approaching the original scope of information science.

So, while Meadows was essentially correct in his analysis reproduced above, there are some signs that the principles of information science are being (in a sense) recognized and rediscovered mainly, perhaps, in the world of librarianship. Sir Nigel Shadbolt (co-founder with Sir Tim BernersLee of the Open Data Institute in the UK) has said, addressing CILIP at its annual conference: "As organizations increasingly recognize the value of open data, so will professional opportunities increase and information workers will be well-placed to take advantage. There is already a lack of skilled people to fill the roles and this will only get worse." There are corresponding signs that librarians are making real efforts to embrace information technology. One American website article (Barclay, 2016) claims, under the title "Has the library outlived its usefulness in the age of the Internet" that, despite severe cuts in funding, the number of public libraries has increased and that academic libraries are sharpening their services; for example "Grand Valley State University's 'Knowledge Market' provides students with peer consultation services for research, writing, public speaking, graphic design and analysing quantitative data". In a similar, but even more radical development in the UK (Allen, 2016),

Europe's first integrated public and university library is housed in the modern Hive building in Worcester alongside the local archive and archaeology service and the County Council's services hub [...] the library's front line team is completely integrated, with some staff being employed by the University and some by the County Council.

A key feature of this initiative is to engage students in new ways, involving them in shaping library services of the future, and already they are producing guides to library use that differ from those produced by the staff.

These two bottom-up initiatives should be strongly supported by the professional associations which should also collaborate more closely with each other, adapting their own world-views and adopting a more flexible, less conservative approach to the demands of this rapidly changing information environment. The dream would be to have a single over-arching national professional association covering all the closely related information activities, including at least librarianship, information science, records management, archives management and museums documentation, as well as aspects of web-page design and, of course, LOD. There is an interesting potential model for this range of applications and techniques, one provided for self-employed information workers - the Association of Independent Information Professionals (AIIP) which states "What IIPs have in common is the ability to provide timely, accurate, and actionable information, analysis, design, review, and strategy to a diverse set of clients across a wide range of sectors" (Ojala, 2016).

Though, as Meadows said, information science may no longer be a separate entity, its basic tenets are still valid - even in the new and still changing information environment. To a large extent, those tenets are also valid for the work of the other information professionals mentioned above; and for many others who find themselves working as authors, intermediaries and searchers in the information chain. While, for example, academics are well served it is vital that new initiatives based on these tenets are nourished so that a better informed society may emerge, and it is encouraging to see such initiatives as have been discussed above such as Full Fact and Snopes. Increasingly, the individual - as employee, voter, 
family member, and member of different economic. cultural and ethnic groups - derives much of his or her information directly or indirectly from the mass media of which the Internet is increasingly dominant. The resultant potential overload of information, much of it poorly accessed and assessed could, with the right efforts, perhaps be improved for the benefit of all.

\section{References}

Allen, Katherine (2016). Students improvingservices for themselves. // Information Today Europe. 13may 2016. www.infotoday.eu/Articles/Editorial/Featured-Articles/Stu dents-improving-services-for-themselves-111071.aspx (last accessed 18 May 2016

Ball, Philip (2014). Wisdom of the crowd: the myths and the realities. // BBC Future. 8 July 2014. www.bbc.com/future/story/20140708-when-crowd-wisdom-goes-wrong (last accessed 12.5.16)

Baraniuk, Chris (2016). World Wide Warp. // New Scientist. 20 (February 2016) 38-41.

Barclay, Donald A. (2016). Has the library outlived its usefulness in the age of Internet? You'd be surprised. // The conversation. April 28, 2016. https://theconversation.com/has-the-library-outlived-its-usefulness-in-theage-of-the-internet- youd-be-surprised-58198. (2016-0518)

Eco, Umberto (2002). On the Press: Five Moral Pieces. London: Vintage.

Europea. www.europeana.eu/portal (last accessed 20.4.16)

Foster, Allan (2014). Initiatives. // Business Information Review. 31:2 (June 2014) 122-139.

Garcia-Marco, Francisco-Javier (2016). Enhancing the visibility and relevance of thesauri in the web: searching for a 'hub' in the linked data environment. // Knowledge Organization. 43:3 (2016) 193-202.

Karpersky Lab (2015). The Rise and Impact of Digital Amnesia. https://blog.kaspersky.com/files/2015/06/005-Kasper sky-Digital-Amnesia-19.6.15.pdf (2016-04-12)

Lehmann, Jens et al. (2012). DBpedia: a large-scale, multilingual knowledge base extracted from Wikipedia. // Semantic Web. 1 (2012) 1-5.

Meadows, A.J. (2009). Fifty years of UK research in information science. // Gilchrist, A. (Editor). Information Science in Transition. London: Facet Publishing.

Noveck, Beth Simone (2015). Smarter Citizens, Smarter State. Harvard: Harvard University Press.

Ojala, Marydee (2016). AlIP explores partnering for success. // Information Today Europe. 3 May 2016. www.infotoday.eu/Articles/Editorial/Featured-Articles/AIIP-explorespartnering-for-success- 110803.aspx. (last accessed 18 May 2016).

Surowiecky, James (2004). The Wisdom of Crowds. New York: Doubleday.

Taylor, Arthur (2012). A study of the information search behaviour of the millennial generation. // Information Research. 17:1 (March 2012).

Vickery, Brian C.; Alina Vickery (2004). Information Science in Theory and Practice. Third revised and enlarged edition. München: K.G.Saur.

Warburton, Nigel (2009). Free Speech. Oxford. Oxford University Press.

Zimmermann, Jens (2015). Hermeneutics. Oxford: Oxford University Press.

Enviado: 2016-06-23. Segunda versión: 2016-08-17. Aceptado: 2016-09-01. 